\title{
Nutrient Release from Disturbance of Infiltration System Soils during Construction
}

\author{
Daniel P. Treese, ${ }^{1}$ Shirley E. Clark, ${ }^{1}$ and Katherine H. Baker ${ }^{2}$ \\ ${ }^{1}$ Environmental Engineering Program, Penn State Harrisburg, Middletown, PA, USA \\ ${ }^{2}$ Life Sciences Program, Penn State Harrisburg, Middletown, PA, USA \\ Correspondence should be addressed to Shirley E. Clark, seclark@psu.edu
}

Received 31 July 2011; Revised 15 November 2011; Accepted 16 December 2011

Academic Editor: Cumaraswamy Vipulanandan

Copyright (C) 2012 Daniel P. Treese et al. This is an open access article distributed under the Creative Commons Attribution License, which permits unrestricted use, distribution, and reproduction in any medium, provided the original work is properly cited.

\begin{abstract}
Subsurface infiltration and surface bioretention systems composed of engineered and/or native soils are preferred tools for stormwater management. However, the disturbance of native soils, especially during the process of adding amendments to improve infiltration rates and pollutant removal, may result in releases of nutrients in the early life of these systems. This project investigated the nutrient release from two soils, one disturbed and one undisturbed. The disturbed soil was collected intact, but had to be airdried, and the columns repacked when soil shrinkage caused bypassing of water along the walls of the column. The undisturbed soil was collected and used intact, with no repacking. The disturbed soil showed elevated releases of nitrogen and phosphorus compared to the undisturbed soil for approximately 0.4 and $0.8 \mathrm{~m}$ of runoff loading, respectively. For the undisturbed soil, the nitrogen release was delayed, indicating that the soil disturbance accelerated the release of nitrogen into a very short time period. Leaving the soil undisturbed resulted in lower but still elevated effluent nitrogen concentrations over a longer period of time. For phosphorus, these results confirm prior research which demonstrated that the soil, if shown to be phosphorus-deficient during fertility testing, can remove phosphorus from runoff even when disturbed.
\end{abstract}

\section{Introduction}

To decrease the volume of stormwater runoff reaching already-degraded urban streams, many localities in the US are either mandating or encouraging the use of green infrastructure. Infiltration is a primary component of green infrastructure/low-impact development because it restores some of the natural hydrologic function to urbanized areas by introducing water back to the groundwater, either through surface or subsurface devices. Infiltration systems also have the potential to remove some of the pollutants transported in urban runoff and reduce their discharge to surface receiving waters through the interaction of pollutants and the infiltration media. Many state guidance documents describe the ideal media characteristics for this pollutant removal.

One concern with the heavy reliance on infiltration systems for pollutant removal is the potential for groundwater contamination. Papers of Pitt et al. [1,2] and Clark et al. [3] contain extensive literature reviews on known and modeled impacts of stormwater infiltration on groundwater quality. Clark and Pitt [4] illustrate two levels of modeling that can be performed to evaluate whether groundwater contamination is a concern, and, if so, how long before pollutants are estimated to reach the groundwater.

The focus of much of the research on groundwater contamination from stormwater infiltration has been on the fate of stormwater pollutants. Little attention has been paid to the components of the media mix itself. Guidance documents often specify that the native soil be incorporated into the media mixture. First, this assumes, or requires that testing demonstrate, that the native soil is not contaminated. Second, it assumes that disturbing the soil to incorporate more organic matter and/or sand for improved removal and hydraulic stability will not have negative impacts on the water passing through the filter.

Leaching of nutrients has been observed from newly constructed infiltration devices [5-7], as well as from engineered 
filter media [8]. This leaching has been assumed to be related to the increased organic matter typically added to the native soil (such as the addition of compost to glacial till resulting in increased phosphorus export, as reported in Pitt et al. [9]). However, a literature review using the Agricola database on soil nutrient release shows that the disturbance of native soils also can release nutrients. For example, a reduction of nutrient pools was observed in tilled soils [10] with the reduction linked to the destruction of soil chemical bonds [11]. The destruction of these bonds between soil aggregates reduces soil macropores, increases bulk density, and reduces hydraulic conductivity, with effects that can exist for decades $[12,13]$. Since increased movement of water through soil and removal of pollutants from influent stormwater are the priorities of infiltration system designers, the effects of disturbance should be of concern. This research is designed to address two of those concerns: the magnitude of the pollutant release from the media and the temporality of the release.

\section{Materials and Methods}

The soil selected for testing was a Wharton silt loam from central Pennsylvania. In the field, 21 ten-centimeter diameter columns of the soil were encased in $0.8 \mathrm{~m}$ length PVC pipe and removed intact from the sampling site. The collection location was a sloped field with a shallow soil that is less than $1 \mathrm{~m}$ to bedrock. Currently, the land is maintained as a lawn but there has been agricultural activity in the past and plowing may have occurred. The visible $\mathrm{O}$ horizon was $3 \mathrm{~cm}$ deep but was exaggerated to $7.5 \mathrm{~cm}$ in the $\mathrm{O}$ horizon columns to keep the soil intact; the final $\mathrm{O}$ horizon consisted of the visible $\mathrm{O}$ horizon and the transition to the A horizon. The $\mathrm{A}$ and $\mathrm{B}$ horizons were moderately rocky. Once the columns were returned to the laboratory, the soil profile was separated into layers by slicing off a portion of the top or bottom of the encased soil, depending on the horizon desired for testing. Five columns were used for each horizon group $(\mathrm{O}$, $\mathrm{A}, \mathrm{AB}$, and entire profile) testing with one column used as the control or pretesting soil condition. Vegetation that was extracted with the columns was cut at the level of the soil surface and removed. The vegetation was not weeded because of the concern for disturbing the soil.

Within two days of returning the soils to the laboratory and separating the columns into the specified horizons, it was observed that the soil had shrunk away from the walls of the pipe in all columns. New samples were collected at the same location; however, even though they were covered to maintain moisture in the soil profile, shrinkage was observed. Therefore, a second local soil of similar quality for $\mathrm{pH}$ and organic content, as reported in the USDA/NRCS soil surveys, with similar geographic location and accessibility, was selected for comparison with the silt loam. The soil selected was a Leetonia loamy sand, again collected from central Pennsylvania (Table 1). Both soils are listed as moderately well drained to well drained. The Leetonia loamy sand columns were collected from a wooded section of state gameland, about 15 meters from a timber harvest landing and 100 meters from abandoned strip mines. The O horizon was $10 \mathrm{~cm}$ deep and consisted almost entirely of deciduous forest canopy leaf litter with the root mass of a forest meadow grass species. After removing the leaf litter, the visible $\mathrm{O}$ horizon was approximately $7-8 \mathrm{~cm}$ deep. The A horizon was very sandy and mostly rock free. Impenetrable compaction was encountered at a depth of about 30 centimeters.

As noted in Table 1, the CECs are different between the two soils with the loamy sand having a higher sand content, which should reduce shrinkage. Because the concern for this investigation was nutrient leaching, it was more important that the organic content be similar since the organic content should be the primary source of nitrogen and phosphorus leaching. When these samples were returned to the laboratory, each soil was analyzed by horizon to confirm the information found in the USDA Soil Survey. These results also are included in Table 1.

For the silt loam soil, the laboratory disturbance consisted of extracting the soil from the column, separating it into $7.5-\mathrm{cm}$ layers, air drying, and repacking without compaction except from the weight of the soil above any layer. While this procedure is more rigorous in terms of not compacting the soil than the field construction of infiltration systems, it is similar in its intent.

The test water for this project was stormwater runoff collected from the Penn State Harrisburg campus. Approximately once a week, $600 \mathrm{~mL}$ (equivalent to $75 \mathrm{~mm}$ of runoff on the soil surface) was distributed into each column. Given that most infiltration systems are designed at a $5: 1$ or $10: 1$ loading ratio, this $75 \mathrm{~mm}$ of runoff on the soil surface is equivalent to $15 \mathrm{~mm}$ or $7.5 \mathrm{~mm}$ of runoff from a drainage area. These "events" are much smaller than a typical design runoff event; this small loading was selected in order to evaluate the change in nutrient release over much smaller time steps to determine the length of time (measured as a water loading) for which nutrient release could be expected. Infiltration through the columns was by gravity only; no artificial pressure was applied to either the top or bottom of the columns. Hydraulic head was maintained between 2.5 and $7.5 \mathrm{~cm}$. Each soil type received a total of 40 simulated storm events over the course of one year.

Samples of the influent and effluent from each column were collected weekly and the effluent volumes recorded. Water quality tests included $\mathrm{pH}$ and conductivity, total hardness (calcium/magnesium) by titration, and turbidity, color, total nitrogen, total phosphorus (phosphate), potassium, and sulfur (sulfate). All samples were collected and analyzed according to approved US EPA protocols and/or Standard Methods for the Examination of Water and Wastewater [14].

At the start and end of the project, plus four times throughout the project, a column of each representative test group $(\mathrm{OAB}, \mathrm{O}, \mathrm{A}, \mathrm{AB})$ was sacrificed for soil testing at the Penn State College of Agricultural Sciences Agricultural Analytical Services Lab. Each sacrificed column was subdivided into $7.5 \mathrm{~cm}$ segments and tested for soil $\mathrm{pH}$, soluble salts, total carbon and total nitrogen through combustion, and phosphorus, potassium, magnesium, calcium, zinc, copper, and sulfur by Mehlich 3 extraction and ICP analysis.

The data below are presented as ratios of the effluent to influent concentration. $C_{E} / C_{0}$ values greater than 1 indicate 
TABLE 1: Comparison of silt loam and loamy sand from USDA Soil Survey and analytical testing.

\begin{tabular}{lcc}
\hline & Silt loam & Loamy sand \\
\hline USDA Soil Survey Information & & \\
Soil pH & $4.0-5.0$ & $3.6-5.0$ \\
Organic content & $1-4 \%$ & $1-5 \%$ \\
Cation Exchange Capacity [CEC] (meq/100 g) & $3.8-8.0$ & $0.6-2.0$ \\
Results of soil fertility analysis & & \\
Soil pH & O horizon: 4.5 & O horizon: 4.7 \\
& AB horizon: 5.7 & AB horizon: 4.7 \\
Organic content & O horizon: $5.5 \%$ & O horizon: $9.5 \%$ \\
& AB horizon: $1.8 \%$ & AB horizon: $1.4 \%$ \\
Cation Exchange Capacity $[\mathrm{CEC}](\mathrm{meq} / 100 \mathrm{~g})$ & O horizon: 19 & O horizon: 15 \\
& AB horizon: 12 & AB horizon: 11 \\
Total nitrogen $(\mathrm{mg} / \mathrm{kg})$ & O horizon: 2,900 & O horizon: 4,700 \\
& AB horizon: 1,000 & AB horizon: 700 \\
Total phosphorus $(\mathrm{mg} / \mathrm{kg})$ & O horizon: 35 & O horizon: 16 \\
& AB horizon: 5 & AB horizon: 2 \\
\hline
\end{tabular}

that the soil is releasing nutrients, whereas values less than 1 indicate removal from the influent water. Because these are two different soils in terms of USDA textural class and of soil chemical characterization, they cannot be compared statistically.

\section{Results and Discussion}

This paper focuses on the nutrient release from each of the two soil types and from the organic $(\mathrm{O})$ and mineral $(\mathrm{AB})$ horizons since nutrient release is the issue of concern for both surface and groundwater contamination. The full data set may be found in Treese [15]. Because the two soils had different extraction depths, the graphs and discussion below are based on common locations in the soil profile. The $\mathrm{O}$ horizon data corresponds to the results obtained from the 0 $7.5 \mathrm{~cm}$ section of each soil, while the $\mathrm{AB}$ horizon corresponds to the results at the $15-22.5 \mathrm{~cm}$ section.

3.1. Total Phosphorus (TP). Figure 1(a) compares the trends in phosphorus effluent quality for the $\mathrm{O}$ horizons of the two soils. Initially, the organic horizon of both soils released phosphorus. However, the disturbed soil had a substantially higher release ( 2.5 to 3 times the influent) until approximately $0.4 \mathrm{~m}$ of stormwater had been applied. The undisturbed soil also had a higher initial phosphorus effluent concentration (approximately 1.5 times the influent) for the same $0.4 \mathrm{~m}$ of stormwater, but it was approximately half of the disturbed soil values. After the $0.4 \mathrm{~m}$ of stormwater has been applied, the disturbed and undisturbed organic horizons are indistinguishable in their performance. Excess phosphorus is washed rapidly from the soil profile. The soil fertility testing of these two horizons found that these soils contained an excess of phosphorus for typical crops. This indicates that there is a reservoir of phosphorus available for leaching. The initial soil P concentrations showed that the disturbed soil had approximately twice as much as phosphorus as the undisturbed soil, so attributing the phosphorus release to only disturbance is not possible.

Figure 1(b) compares the two mineral horizons. Generally, the mineral layers of the two soils provided some removal of phosphorus, with the greater removal being seen with the undisturbed soil. The mineral layers removed approximately $50 \%$ of the total phosphorus applied for the undisturbed soil and 30\% applied to the disturbed soil. Therefore, an infiltration system that incorporated both the organic and mineral layers would be expected to remove phosphorus slightly, even after disturbance. However, extracting and reusing only the organic and topsoil (A horizon where organic leaching has occurred) layers could result in either no removal or the release of phosphorus from the soil if it is not taken up by any vegetation. Because the soil concentration of extractable phosphorus was large, this initial release of phosphorus into the passing water was not visible as a decrease in soil phosphorus concentration in the soil analyses (Figure 2).

Generally, these results are in agreement with the literature on long-term phosphorus behavior in agricultural and forest soils, although no prior studies have investigated the short-term behavior of phosphorus at the resolution used in this study. The silt loam had higher initial phosphorus content than the loamy sand (twice as high), as would be expected since the loamy sand had more sand in the mixture. However, the loamy sand had a much higher initial organic content. For phosphorus, this higher initial concentration and the disturbance of the soil had a very limited impact ( $0.4 \mathrm{~m}$ of cumulative loading). This agrees with Boem et al. [16] who observed that there was no difference in total phosphorus, available phosphorus, or phosphorus sorption indexes in the upper $5 \mathrm{~cm}$ of tilled and no-till agricultural soils despite a $14 \%$ increase of total OM and $56 \%$ increase of particulate OM in no-till soils. This indicates that organic matter content may not impact phosphorus leaching. 


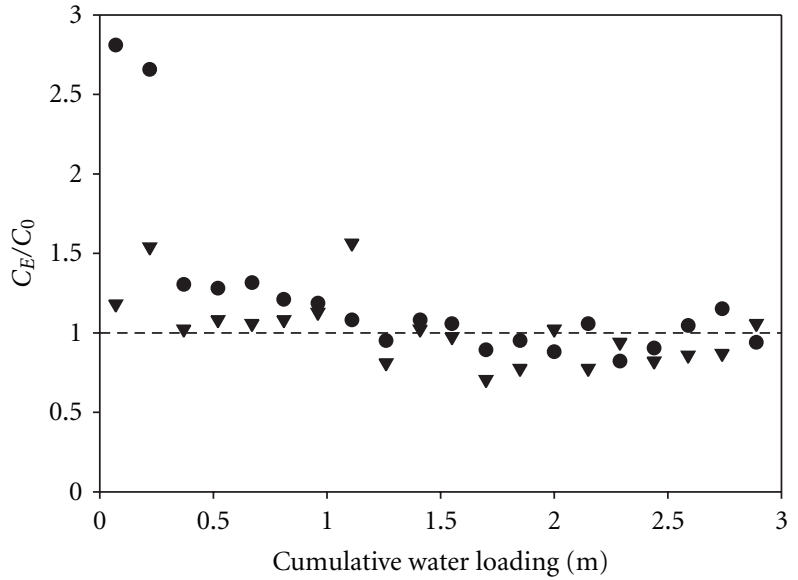

(a)

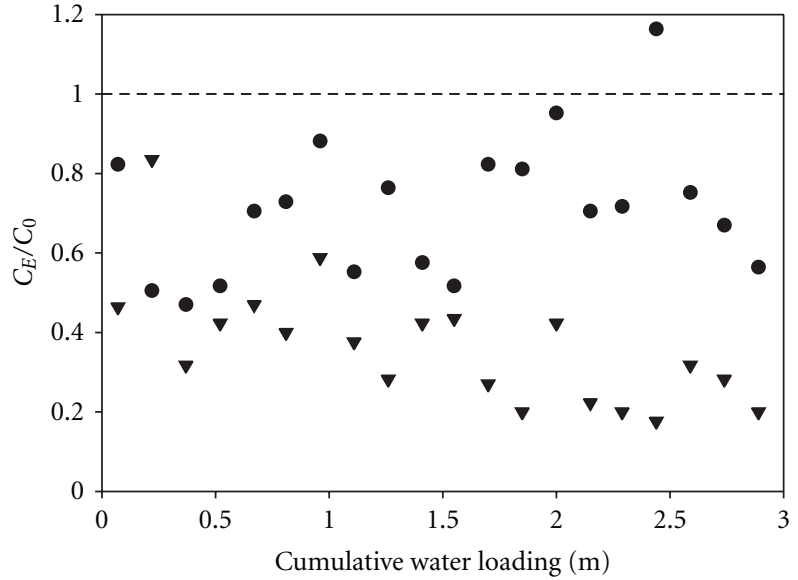

- Disturbed silt loam

V Intact loamy sand

(b)

Figure 1: Phosphorus export from (a) organic horizon and (b) mineral horizon.

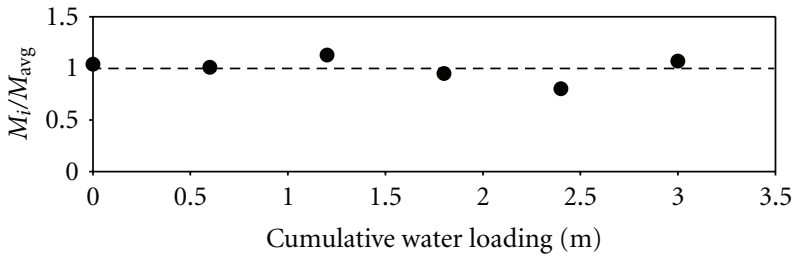

(a)

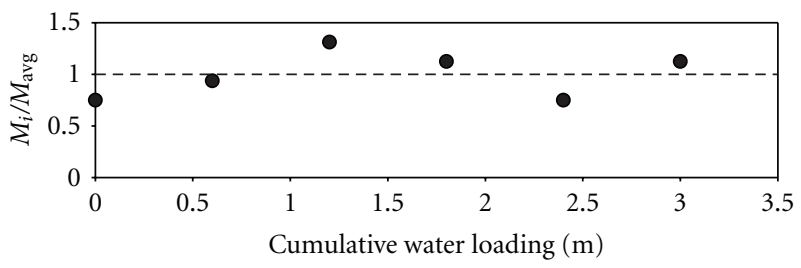

(c)

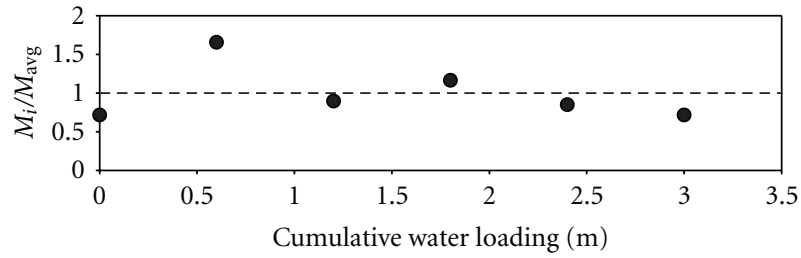

(b)

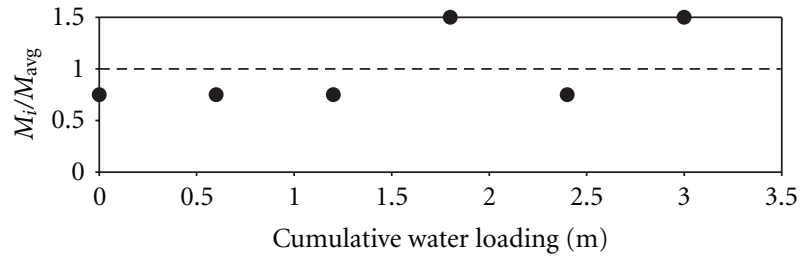

(d)

FIGURE 2: Ratio of sample soil results for phosphorus for (a) disturbed O horizon, (b) undisturbed O horizon, (c) disturbed AB horizons, and (d) undisturbed $\mathrm{AB}$ horizons.

These results also illustrated the impact of the initial phosphorus content of soils on phosphorus release. Both soils had an initial release from the organic layer, and a removal from the passing water in the mineral layers. Increased retention of phosphorus by subsurface soils has been noted before in both forest soils [17] and no-till agricultural soils. It was assumed to result from the fact that subsurface soils were not saturated with phosphorus [18]. This removal by the subsurface layers recently has been correlated with other factors. Differences in phosphorus retention by the mineral soil horizon have been correlated with soil mineralogy, with improved retention seen by aluminum-bearing minerals [19]. Calcium, magnesium, and aluminum have been shown to have a direct effect on phosphorus retention in the organic horizon with cation exchange capacity, $\mathrm{pH}$, carbonate, organic carbon, sand content, silt content, and clay content having indirect correlations [20]. This appears to be partly due to the formation of calcium-phosphate-clay cement bridges between soil aggregates [21]. Disturbance breaks up the larger soil clumps into smaller particles, increasing the surface area available for reaction with water. These reactions include hydration and ion exchange. These surface reactions change the surface chemistry, breaking bonds [11], which may result in excess release of calcium [10]. Specifically for engineered bioretention soils, Hunt et al. [7] recommended soils with a low $P$-index value, which translates into soils that are considered deficient in phosphorus in a soil fertility test. The organic layers of these soils were considered sufficient or high for phosphorus content for soil fertility while both mineral layers were considered deficient.

The rapid decrease of the initially elevated effluent phosphorus concentrations in this study correlates well 


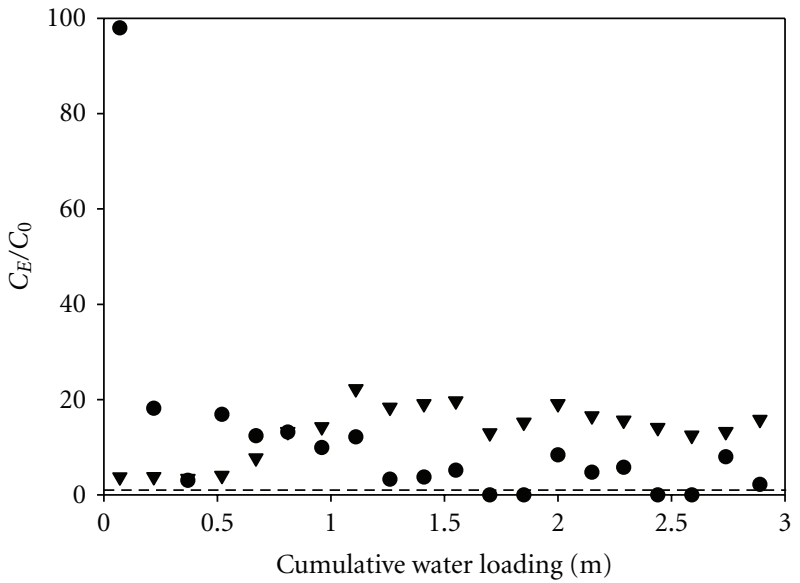

(a)

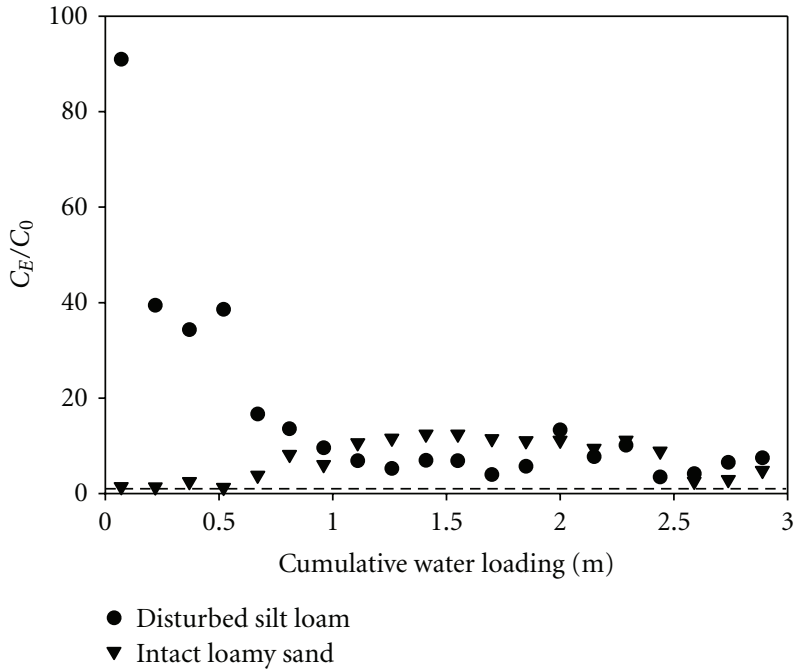

(b)

FIGURE 3: Nitrogen export from (a) organic horizon and (b) mineral horizon.

with the trends observed from other elements leached from the disturbed soil's organic horizon plus the trends in the aggregate ionic measurement of conductivity (data not shown). For phosphorus, it appears that disturbance may have no impact on phosphorus release by itself, but instead the initial phosphorus release results from initial soil concentrations in excess of plant needs. Initial releases are substantially higher in both soils; however, the $0.4 \mathrm{~m}$ of runoff loading would be less runoff than would be expected during a single large storm.

3.2. Total Nitrogen. Compared to the total phosphorus, the initial release of total nitrogen from both the organic and mineral horizons of the disturbed soil was very high (100 times the influent concentration) and lasted approximately twice as long (approximately $0.8 \mathrm{~m}$ of runoff loading), despite the lower initial concentration of nitrogen in the disturbed soil (Figure 3). In contrast to the total phosphorus results, the undisturbed soil saw a delayed elevated release of total nitrogen. For the phosphorus, the release decreased or remained constant over time, whereas the total nitrogen saw an increase after approximately $0.4 \mathrm{~m}$ of runoff loading. This delayed release indicates that there potentially was a reservoir of nitrogen available for release or uptake by plants, but its transport through the soil was retarded for undetermined reasons. The disturbance of the soil accelerated that release potentially by breaking any chemical bonds that detained the nitrogen in the soil profile. Once this available nitrogen was released, it rapidly exited the column and the nitrogen effluent concentration asymptotically approached the influent concentration. Not disturbing the soil appears to reduce the magnitude of this release but does not prevent it. Figure 4 illustrates the change in soil nitrogen concentration as a function of loading. For the disturbed soils, there appears to be no trend in the soil nitrogen concentration; however, for the undisturbed soil, it appears that there could be a slight reduction in soil nitrogen over time that corresponds to the delayed elevated nitrogen release from this soil. Given the lack of soil analysis replication at the individual water loadings, additional analysis would be required to confirm this trend and document its magnitude.

This higher effluent concentration from the disturbed soil columns occurs despite the initial $\mathrm{O}$ horizon nitrogen concentration and total organic content of the disturbed silt loam soil being approximately $60 \%$ of the concentration in the undisturbed loamy sand. A release of nitrogen from soils which were dried, sieved, and then repacked has been published and linked to bound nitrogen (12-27\% contribution) in the upper $2 \mathrm{~cm}$ of tilled and no-till soils with greater release from the no-till soils of higher organic content [22]. It would appear that the disturbance caused an immediate and very high release of the bound nitrogen in the silt loam. The organic horizon of the undisturbed loamy sand only gradually began to release nitrogen as either the structure degraded [23], or, more likely, as any remaining leaf litter decomposed. These results are in contrast with those of Hsieh and Davis [6], who found that nitrate removal increased with increased organic matter in the media mix. These results showed that the nitrogen release was substantially greater in the organic layer of both the disturbed and undisturbed soils, which had the higher initial nitrogen and organic content.

\section{Conclusions}

The initial substantial leaching of some tested parameters by the silt loam soil columns, which had to be air-dried and repacked, may resemble what occurs after construction of infiltration units. An initial release of nutrients from infiltration system media has been observed before the establishment of vegetation [24] and should be recognized as a concern, even though it appears that this release is of short term. The nitrogen release of the disturbed silt loam soil columns quickly declined but the initial elevated 


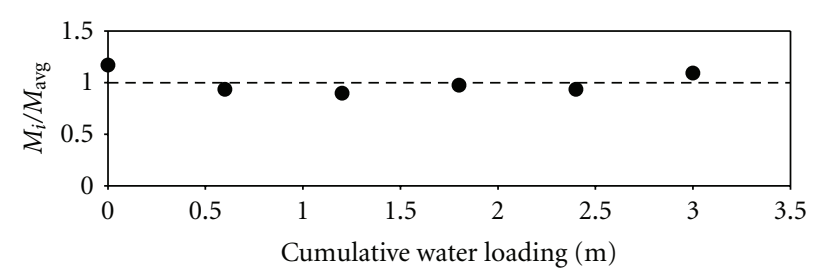

(a)

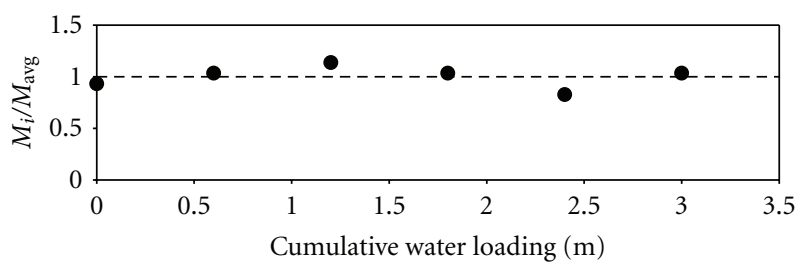

(c)

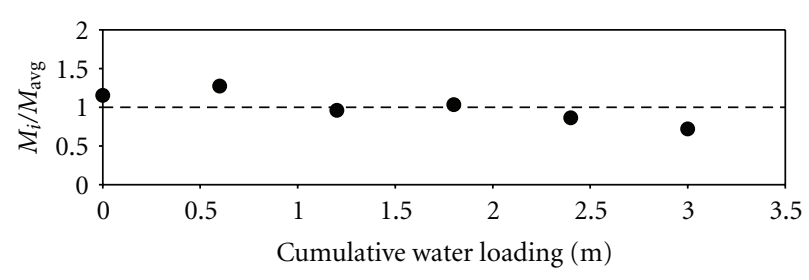

(b)

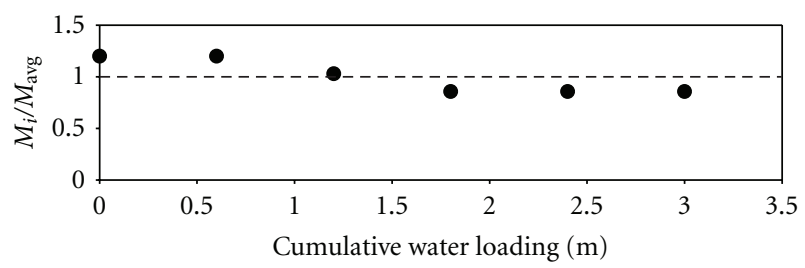

(d)

FIGURE 4: Ratio of sample soil results for nitrogen for (a) disturbed O horizon, (b) undisturbed O horizon, (c) disturbed AB horizons, and (d) undisturbed $\mathrm{AB}$ horizons.

concentrations are well above the U.S. Environmental Protection Agency's drinking water standards. Vegetation may abate these concerns, even during the plant establishment phase, at least to the depth of the root zone. However, this release would be expected for subsurface infiltration systems, such as dry wells and any soil disturbed below devices such as porous pavement.

Phosphorus leaching has been a problem in bioretention systems with underdrains and assumed to be due to disturbance [5] or initially high phosphorus content in organic media [7]. These results indicate that the organic horizon is a source of leaching phosphorus, but lower soil horizons exhibit removal even with disturbance. Given the higher initial phosphorus content in the disturbed soil, it appears that the initial phosphorus release may be primarily a function of initial concentration available for release. The lack of removal and only slightly elevated effluent concentrations from the $\mathrm{O}$ horizon, when combined with the removal of phosphorus by lower horizons, suggest that phosphorus removal is independent of organic matter and is dependent on one or more components of the mineral matter.

This study, with its focus on the early life of soil media, indicates that there are potential concerns with nutrient releases during the early storm events. For infiltration in native soils, this study reinforces the need to evaluate whether soil disturbance is required or whether an area with good infiltration should be left undisturbed. When combined with the results of Clark and Pitt [25] on the nutrient release from the organic matter if the organic part of the media goes anaerobic, these results indicate that the organic content of the infiltration system media should be limited to that needed for plant growth. For subsurface systems, it should be limited to the amount needed to provide the desired pollutant removal for the lifespan of the device before maintenance and media replacement. These results indicate that the organic content of the organic horizon is large enough for nitrogen release to occur and that, for unvegetated systems, the organic content should be minimized.

\section{References}

[1] R. Pitt, S. Clark, K. Parmer, and R. Field, "Groundwater contamination from stormwater infiltration," U.S. EPA Report, 1995.

[2] R. Pitt, S. Clark, K. Parmer, and R. Field, Groundwater Contamination from Stormwater Infiltration, Ann Arbor, Chelsea, Mich, USA, 1996.

[3] S. E. Clark, K. H. Baker, D. P. Treese, J. B. Mikula, C. Y. S. Siu, and C. S. Burkardt, Sustainable Stormwater Management: Infiltration vs. Surface Treatment Strategies, Water Environment Research Foundation, 2010, Project Number 04-SW-3.

[4] S. E. Clark and R. Pitt, "Influencing factors and a proposed evaluation methodology for predicting groundwater contamination potential from stormwater infiltration activities," Water Environment Research, vol. 79, no. 1, pp. 29-36, 2007.

[5] M. E. Dietz and J. C. Clausen, "A field evaluation of rain garden flow and pollutant treatment," Water, Air, and Soil Pollution, vol. 167, no. 1-4, pp. 123-138, 2005.

[6] C. Hsieh and A. P. Davis, "Evaluation and optimization of bioretention media for treatment of urban storm water runoff," Journal of Environmental Engineering, vol. 131, no. 11, pp. 1521-1531, 2005.

[7] W. F. Hunt, A. R. Jarrett, J. T. Smith, and L. J. Sharkey, "Evaluating bioretention hydrology and nutrient removal at three field sites in North Carolina," Journal of Irrigation and Drainage Engineering, vol. 132, no. 6, pp. 600-608, 2006.

[8] S. E. Clark, Urban stormwater filtration: Optimization of design parameters and a pilot-scale evaluation, Ph.D. dissertation, The University of Alabama at Birmingham, 2000.

[9] R. Pitt, R. Harrison, J. Lantrip, and C. L. Henry, "Infiltration through disturbed urban soils and compost-amended soil effects on runoff quality and quantity," in Proceedings for the Water Environment. Federation's 72nd Annual Conference and Exposition (WEFTEC '99), New Orleans, La, USA, 1999.

[10] B. R. Stinner, D. A. Crossley, E. P. Odum, and R. L. Todd, "Nutrient budgets and internal cycling of N, P, K, Ca and Mg in conventional tillage, no-tillage, and old-field ecosystems on 
the Georgia Piedmont," Ecology, vol. 65, no. 2, pp. 354-369, 1984.

[11] D. H. Powers and E. L. Skidmore, "Soil structure as influenced by simulated tillage," Soil Science Society of America Journal, vol. 48, no. 4, pp. 879-884, 1984.

[12] R. Pitt, S. E. Chen, S. E. Clark, J. Swenson, and C. K. Ong, "Compaction's impacts on urban storm-water infiltration," Journal of Irrigation and Drainage Engineering, vol. 134, no. 5, pp. 652-658, 2008.

[13] K. N. Potter, F. S. Carter, and E. C. Doll, "Physical properties of constructed and undisturbed soils," Soil Science Society of America Journal, vol. 52, no. 5, pp. 1435-1438, 1988.

[14] APHA (American Public Health Association), Standard Methods for the Examination of Water and Wastewater, American Public Health Association, Washington, DC, USA, 17th edition, 1989.

[15] D. P. Treese, Pollutant transport within the vadose zone of natural soils, Master's of Environmental Engineering Paper, Penn State Harrisburg, 2009.

[16] F. H. G. Boem, C. R. Alvarez, M. J. Cabello et al., "Phosphorus retention on soil surface of tilled and no-tilled soils," Soil Science Society of America Journal, vol. 72, no. 4, pp. 11581162, 2008.

[17] H. Riekerk, "The mobility of phosphorus, potassium, and calcium in a forest soil," Soil Science Society of America Journal, vol. 35, pp. 350-356, 1971.

[18] E. A. Guertal, D. J. Eckert, S. J. Traina, and T. J. Logan, “Differential phosphorus retention in soil profiles under no-till crop production," Soil Science Society of America Journal, vol. 55, no. 2, pp. 410-413, 1991.

[19] C. J. Penn, G. L. Mullins, and L. W. Zelazny, "Mineralogy in relation to phosphorus sorption and dissolved phosphorus losses in runoff," Soil Science Society of America Journal, vol. 69, no. 5, pp. 1532-1540, 2005.

[20] D. V. Ige, O. O. Akinremi, and D. N. Flaten, "Direct and indirect effects of soil properties on phosphorus retention capacity," Soil Science Society of America Journal, vol. 71, no. 1, pp. 95-100, 2007.

[21] J. L. Ragland and W. A. Seay, "The effects of exchangeable calcium on the retention and fixation of phosphorus by clay fractions of soil," Soil Science Society Proceedings, vol. 21, article 261, 1957.

[22] H. L. Kristensen, G. W. McCarty, and J. J. Meisinger, "Effects of soil structure disturbance on mineralization of organic soil nitrogen," Soil Science Society of America Journal, vol. 64, no. 1, pp. 371-378, 2000.

[23] J. J. Schoenau and J. R. Bettany, "Organic matter leaching as a component of carbon, nitrogen, phosphorus, and sulfur cycles in a forest, grassland, and gleyed soil," Soil Science Society of America Journal, vol. 51, no. 3, pp. 646-651, 1987.

[24] W. C. Lucas and M. Greenway, "Nutrient retention in vegetated and nonvegetated bioretention mesocosms," Journal of Irrigation and Drainage Engineering, vol. 134, no. 5, pp. 613623, 2008.

[25] S. E. Clark and R. Pitt, "Storm-water filter media pollutant retention under aerobic versus anaerobic conditions," Journal of Environmental Engineering, vol. 135, no. 5, pp. 367-371, 2009. 

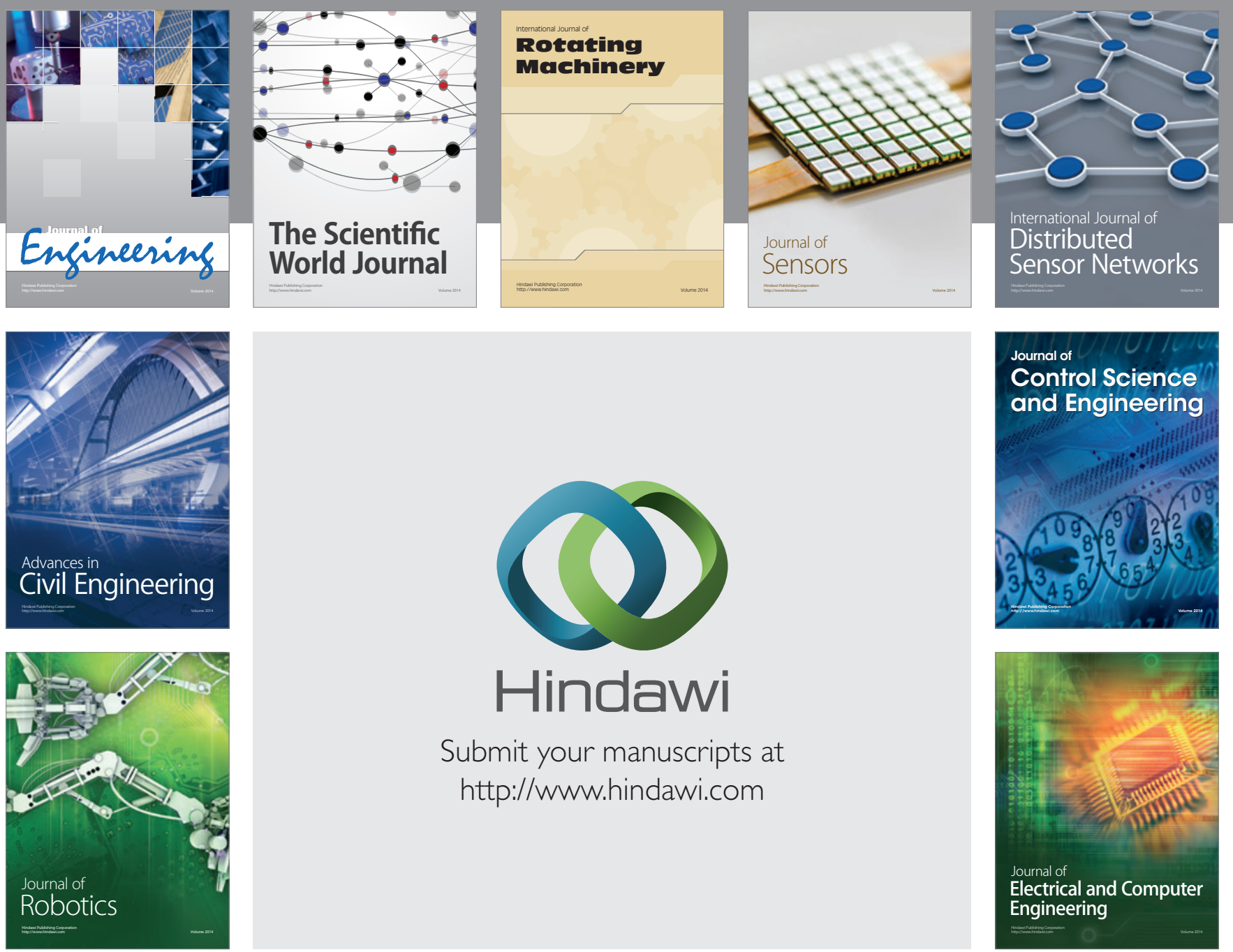

Submit your manuscripts at

http://www.hindawi.com
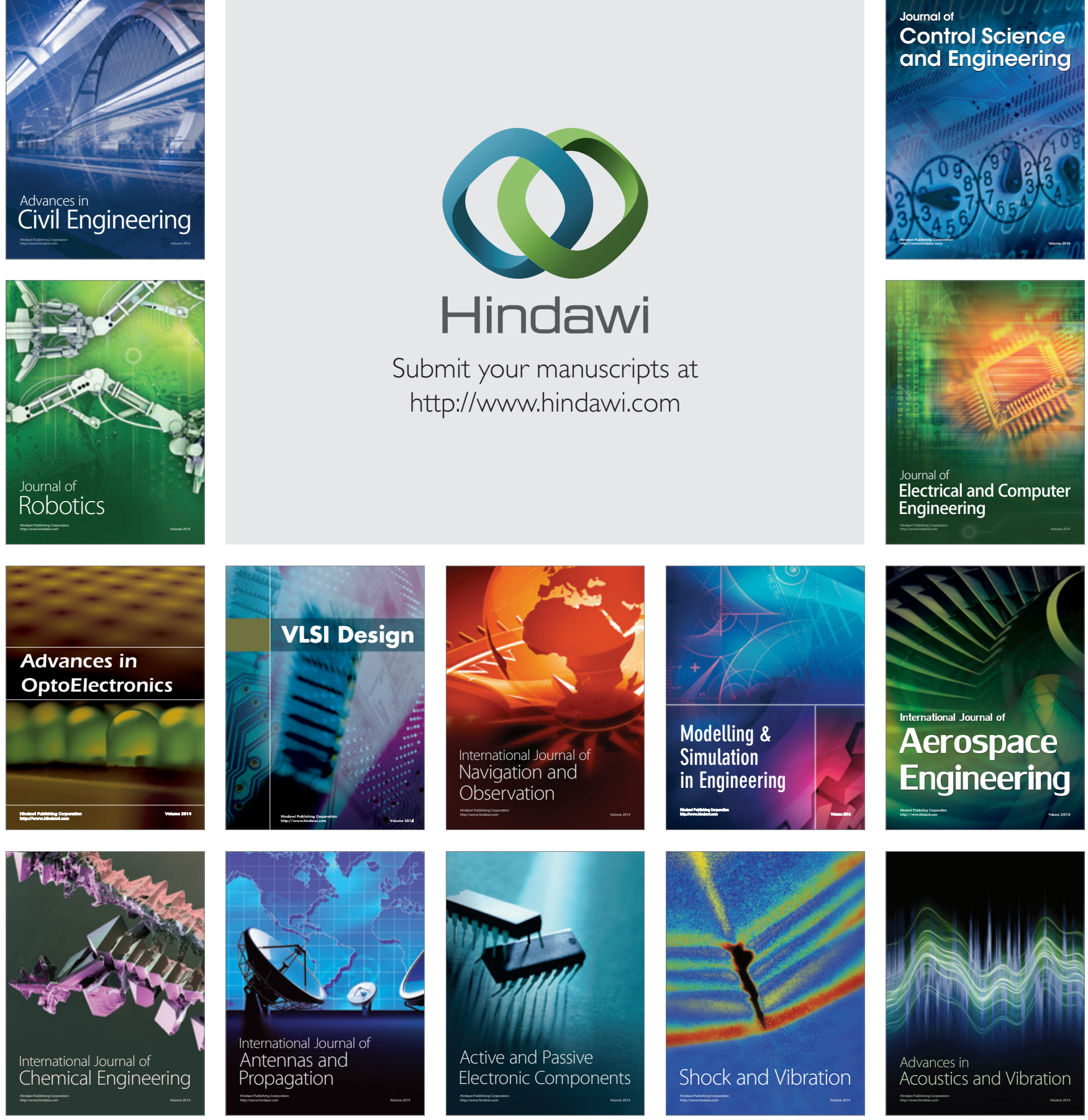